\title{
OS AVANÇOS NO RIO GRANDE DO SUL POR MEIO DE POLÍTICAS PÚBLICAS QUE EFETIVAM O DIREITO À SAÚDE: UM OLHAR ATRAVÉS DO PROGRAMA DE ASSISTÊNCIA AO INFANTE MENOR DE SEIS ANOS
}

\author{
$*$ \\ Cleidiane Sanmartim \\ Universidade de Santa Cruz do Sul - UNISC - Brasil \\ Josiane Borghetti Antonelo Nunes \\ Universidade de Santa Cruz do Sul - UNISC - Brasil
}

\begin{abstract}
Resumo
O presente estudo tem como objetivo principal analisar o papel das políticas públicas de atendimento de crianças e adolescentes, bem como o papel da responsabilidade entre os três atores principais na garantia de direitos desses infantes: Estado, família e sociedade. $\mathrm{O}$ reconhecimento do papel desses atores é importante para garantir de forma eficiente a proteção integral das crianças e adolescentes que se encontram em condição peculiar de desenvolvimento. De olho neste aspecto, o Estado do Rio Grande do Sul, de forma pioneira lançou e consagrou uma Política Pública de efetivação dos direitos fundamentais de crianças de zero à seis anos de idade, o PIM -Programa Primeira Infância Melhor. Dessa forma, o estudo da presente política pública, faz-se necessária no sentido de conhecer melhor sua estrutura e abrangência, bem como uma forma de comprovação dos esforços do Estado em atuar nesta seara ainda tão carente de ações efetivas.
\end{abstract}

Palavras-chave: Adolescente; criança; políticas públicas; proteção integral; Programa Primeira Infância Melhor.

\section{Considerações Iniciais}

A história nos traz duras realidades, quando falamos do modelo ideal de sociedade que buscamos, e neste modelo pode-se relacionar o que ensinamos às nossas crianças e adolescentes sobre seus direitos e deveres, muito embora seja difícil, é possível abandonar os traços de violação desses direitos, e seguir em frente com novos modelos de convivência, responsabilidades e lazer, mesmo que nessas páginas se encontre passados amargos e obscuros, de uma época não tão feliz.

Assim, é refletindo sobre este passado que construiremos nosso futuro, com base em novos paradigmas sociais, políticos e econômicos, não esquecendo porém, que toda essa gama 
de novas possibilidades devem ser pensadas e implementadas de forma a garantir a dignidade da pessoa humana.

De forma clara, não podemos desconsiderar os avanços, a fim de evitar um retrocesso, não podemos desconsiderar tudo aquilo que tão arduamente se conquistou objetivando evoluir.

A questão é que não devemos estagnar ou retroceder em nossas conquistas, muito pelo contrário, devemos ter presente que as sérias dificuldades enfrentadas pelo Brasil com a questão das garantias para as crianças e adolescentes já logrou muitos avanços, porém para uma grande parcela da população brasileira acreditam que dar tantos direitos para um adolescente ou à uma criança, gera problemas sociais no futuro, esperando que eles recebam mais do que devem contribuir.

Muito embora este pensamento seja equivocado, isso demonstra que estamos trabalhando num campo de difícil entendimento, e isso ocorre devido a cultura arraigada de escravidão que tivemos, além da alienação de muitas famílias sobre os reais problemas à que a infância é submetida.

Assim sendo, o presente estudo vislumbra a evolução na conquista dos direitos de crianças e adolescentes, bem como a evolução da Saúde no Brasil, e as políticas públicas voltadas à este público, enfatizando a respeito de um Programa do governo do Estado do Rio Grande do Sul, que visa à efetivação dos direitos da criança, valorizando dessa forma seu desenvolvimento sadio.

Essa política pública busca transformar a realidade infantil do Estado, de crianças de zero a seis anos, garantindo a satisfação dos direitos na Primeira Infância, intitulado de PIM Programa Primeira Infância Melhor.

Nesse sentido, é que se discute a partir de uma análise interdisciplinar, a realidade das Políticas Publicas inovadoras que surgiram no Sul de nosso país, bem como a breve análise das conquistas dos direitos das crianças e adolescentes no Brasil e da evolução da saúde.

\section{Um olhar sobre a legislação nacional e a evolução da história dos Direitos da Criança e do Adolescente}

Embora datada de longo período, a história das crianças e adolescentes sofreu com diversos processos de evolução, porém, o interesse por sua efetivação e a necessidade de garantir direitos protecionais para os infantes, bem como a abominação que hoje se vê de 
forma globalizada veio a ter seu início no contexto brasileiro apenas na década de 70, e a partir deste momento é que se passou a vislumbrar com mais veemência a discussão pontual sobre esta problemática. Porém, mesmo que de forma tímida, ainda se busca compreender como e porque tais fatos aconteceram e continuam a acontecer (VERONESE; COSTA, 2006, p.46).

Desse modo, tal preocupação em busca da efetivação dos direitos desses infantes acaba por ser uma vitória conquistada a doses ínfimas visto que antes do século XVII, o infante era totalmente desprovido de significância, passando a ser percebido só a partir do momento em que alcançava o status de adulto, passagem essa que se dava de maneira brusca e precoce (VERONESE, 2003, p.423).

De acordo com Schneider e Ramires é possível vislumbrar uma breve retomada de nossa história frente à luta pela efetivação dos direitos atribuídos aos infantes, que por muito tempo foi suprimida frente a uma visão política assistencialista. A primeira delas, conhecida como a Doutrina do Direito Penal do Menor, inspirava-se nos Códigos Penais de 1830 e 1890 (SCHNEIDER; RAMIREZ, 2007, p.19).

A fim de se comprovar a preocupação recente com a criança e o adolescente, podemos afirmar que o termo criança trata-se de uma palavra contemporânea, inovadora e atual, uma vez que as conquistas são construídas a passos lentos que um dia chegam em seu ápice. Antes do século XVII, os infantes eram tidos sem significância, sendo percebidos apenas quando chegavam a idade adulta, momento esse que se dava de maneira brusca e precoce (VERONESE, 2003).

Cabe salientar que as palavras criança e adolescente surgiram apenas em 1830, no período imperial Brasileiro, que tinham o significado de cria da mulher para as crianças, e Adolescente era um termo pouco usado, denominando os que tinham de 14 a 25 anos atrelados à conquista da maturidade (MAUAD, 2004, p.140).

Um pouco antes disso, em 1726 surgiu a primeira Roda dos Expostos que servia para ali deixar as crianças frutos de relações de adultério ou rejeitadas por seus familiares que ficavam a espera da adoção temporária, na cidade de Salvador. Em 1738, foi à vez do Rio de Janeiro e, posteriormente, em 1789, construíram a de Recife (CUSTÓDIO; VERONESE, 2007).

Como marco da legislação voltada às crianças e adolescentes, em 1919 foi proclamado na Argentina a Lei Agote, e a partir daí que na América Latina iniciou-se a criação de legislação específica para menores, voltada para proteção da infância e juventude (SALIBA, 2006). 
Considera-se esta a fase expressiva da nova forma de entendimento da criança e do adolescente, incorporando os mesmos em nossa legislação, nascendo em 1923 o pioneiro Juízo de menores no Brasil e posteriormente em 1927 a aprovação do Código de Menores ou Código de Mello Mattos, que surge com uma nova ideologia, alterando alguns dispositivos e inovando em outros, uma vez que estabelece a menoridade de dezoito anos, e iniciando uma regulamentação para o trabalho infantil (CUSTÓDIO; VERONESE, 2007).

Nas Constituições de 1934 e 1946, a proteção à infância foi vislumbrada, enfatizando a regulamentação do trabalho infantil, e corroborando a ideia de que todos devem desfrutar do direito à educação, sem distinção, racial, social ou econômica.

O ECA - Estatuto da Criança e do Adolescente (Lei no. 8.069 de 13 de julho de 1990) surge com uma nova perspectiva de proteção integral da Criança e Adolescente, começando pela distinção entre os dois, caracterizando o primeiro como um ser que tem de zero até doze anos incompletos e o segundo - adolescente- se encontra na faixa etária de doze a dezoito anos de idade incompletos (VERONESE, 1999).

Em seguida, tem-se a consagração da Doutrina Jurídica da Situação Irregular, como um princípio, advindo do Código de Menores de 1979 e fundado na proteção do menor abandonado e do menor infrator.

No entanto, no ano de 1948, através da Declaração Universal dos Direitos Humanos, das Nações Unidas, houve um programa protecional de destaque para as crianças, qual seja a postulação da necessidade de se conceder a elas, "direito a cuidados e assistências especiais".

Além destas evoluções, o ano de 1959 foi o momento em que houve a aprovação da Declaração Universal dos Direitos da Criança (UNICEF, 1959) e ela apresentou um segundo princípio onde era destacada a proteção especial visando à oportunidade de se desenvolver de forma saudável e em condições livres e dignas. Destaca-se, ainda, que os direitos estabelecidos nas declarações são utilizados como forma de princípios, não representando obrigações para os Estados, resultado este que é diverso do obtido com as Convenções, que estabelecem políticas legislativas a serem adotadas pelos Estados que dela fazem parte (SCHNEIDER;RAMIREZ, 2007).

A partir da pesquisa histórica é possível vislumbrar uma marcante evolução dos direitos da criança e do adolescente e conforme assentam Veronese e Costa, ao apresentarem que no Brasil Colônia, as crianças indígenas acostumadas com carinhos dos pais acabaram por conhecer, de forma brutal, a raiva dos que aqui chegavam com o ímpeto de mandar e de apossar-se de tudo, inclusive do próprio povo nativo, que frente aos castigos, que lhes eram 
impostos de maneira física, acabaram se negando a continuar com a prestação de seus trabalhos escravos em prol dos exploradores.

Assim, com a falta de mão de obra escrava dos indígenas, adveio a necessidade de trazer negros ao país, os quais se submetiam a tal imposição de trabalho escravo, até pela própria condição de miserabilidade extrema em que se encontravam quando aqui chegavam. Ademais, é sabido que em Portugal também se retrata, na mesma época, a utilização de castigos físicos às crianças, em níveis com superioridade de crueldade, àqueles impostos aos adultos (VERONESE; COSTA, 2006).

Indo adiante, no ano de 1989 foi aprovada por unanimidade a Convenção Internacional dos Direitos da Criança, em sessão de 20 de novembro da Assembleia Geral das Nações Unidas, aprovação esta que só foi possível, após a árdua união de 43 países-membros da Comissão de Direitos Humanos, demonstrando-se com isso, novos avanços. O Brasil ratificou esta Convenção em 24 de setembro de 1990 por intermédio do Decreto $\mathrm{n}^{\circ}$. 99.710 (SCHNEIDER;RAMIREZ, 2007).

Já no que diz respeito a termos constitucionais, somente a partir da atual Constituição Federal os infantes passam a contar com uma inserção legislativa mais contundente, de forma que vários dispositivos legais demonstram a preocupação com a efetivação da criança e do adolescente, no sentido de que os mesmos passem a ter o direito de serem ouvidas, cuidadas e protegidas, como pessoas em condição peculiar de desenvolvimento, tal qual o postulado no princípio da prioridade absoluta. Pode-se apresentar como coroamento do postulado acima a inclusão do artigo $227^{1}$ na nossa Carta Magna e, ainda, outra legislação especial, de igual ou até superior relevância, no que tange à proteção dos infantes, uma vez que é uma lei especial a esta clientela, qual seja, a Lei $n^{\circ} .8 .069$ de 13 de julho de 1990 - Estatuto da Criança e do Adolescente, que fora elaborado com o intuito de assegurar de maneira veemente e firme a defesa dos direitos também assegurados na Constituição Federal (VERONESE; COSTA, 2006).

\footnotetext{
1 Art. 227. É dever da família, da sociedade e do Estado assegurar à criança e ao adolescente, com absoluta prioridade, o direito à vida, à saúde, à alimentação, à educação, ao lazer, à profissionalização, à cultura, à dignidade, ao respeito, à liberdade e à convivência familiar e comunitária, além de colocá-los a salvo de toda forma de negligência, discriminação, exploração, violência, crueldade e opressão. IN: BRASIL. Constituição da República Federativa do Brasil. Brasília, DF, Senado, 1988.
} 


\section{Os caminhos evolutivos da Saúde no Brasil}

Pode-se afirmar que até a década de 80, a saúde no Brasil era uma marca de desigualdade e diferenciação, após a criação das Caixas de Assistência e Previdência, dando limites a esse direito do cidadão, pois apenas os segurados previdenciários é que tinham atendimento médico, bem como seus dependentes, restringindo este atendimento apenas à minoria que estava inserida no mercado de trabalho.

A mudança dessa realidade começou a passos lentos, primeiramente com a criação pelo Governo do FUNRURAL (Fundo de Assistência Rural), o PPA (Plano de Pronta Ação), o PIASS (Programa de Interiorização das Ações de Saúde e Saneamento) e a AIS (Ações integradas de Saúde), incorporando a população rural, a população independente de vínculo previdenciário, expandindo a cobertura de atenção básica à saúde e ampliando a cobertura dos Serviços de Assistência médico-hospitalar à toda a população, sem exceções.

A partir de então, com a unificação da previdência em 1966, a responsabilidade pela Saúde da população, passou a ser da União. Com esta mudança, a autora Maria Inês Ferreira de Miranda destaca:

Em 1962, segundo dados do Instituto Brasileiro de Geografia e Estatística (IBGE)", "o país dispunha de 236.930 leitos hospitalares, sendo que $40 \%$ eram públicos e $60 \%$ privados. Em 1976, dos 462,9 mil leitos existente, $27 \%$ eram públicos e $73 \%$ privados. Já em 1986, a participação dos leitos públicos cai para $22 \%$, enquanto os privados passam a responder por $78 \%$ da capacidade instalada (MIRANDA, 2001, p.19).

Dessa forma é possível perceber uma distribuição desproporcional de leitos, nos hospitais, além da diminuição deles para o setor público, deixando a população desamparada, sem conseguir atendimento adequado, por falta de vagas nos hospitais.

Após este período, veio a crise econômica de 80, que prejudicou vários setores, e principalmente o da Saúde pública. Surge o Plano do Conselho Consultivo da Administração de Saúde Previdenciária, o COONASP, criado em 1982, mas que não deu muito certo, embora tenha transformado algumas das políticas existentes como a AIS e o Sistema Unificado e Descentralizado de Saúde (SUDS), que expandiu e descentralizou os sistemas públicos de saúde municipais e estaduais (BARROS, 1996).

Precisamente no ano de 1986, é que aconteceu movimento pela Reforma Sanitária, buscando reconhecimento da saúde como direito universal, acesso à toda população, entre 
outras reivindicações. Foi na Assembléia Nacional Constituinte que se garantiu a inclusão das reivindicações da Reforma Sanitária na Constituição de 1988, transformando não só a saúde em direito de todos como também uma nova organização estatal da área.

Além disso, quase que concomitantemente, criou-se a lei $n^{\circ} 8.080 / 90$ para a promoção, proteção e recuperação da Saúde, sobre as Constituições Estaduais e as Leis Orgânicas Municipais do SUS (Sistema Único de Saúde), criando também a Lei no 8.142/90, que veio para garantir a participação da comunidade na gestão do SUS entre outras finalidades.

Sendo assim,

[...] a implantação da Reforma se mostrou, de fato, como um processo de formulação da política de saúde, cujo resultado será a consolidação de um sistema hídrico - público e privado -, apesar a definição legal de um sistema único, público, universal e gratuito (MENICUCCI, 2007, p.305).

Esse é o ponto primordial da evolução em saúde no Brasil, onde se transforma o acesso à saúde em um sistema igualitário, através do Sistema Único de Saúde, devendo este ser gratuito, público e para todos. Assim, analisado o histórico da Saúde no Brasil, analisarse-á as políticas públicas, e a promoção dos direitos das crianças e adolescentes por meio delas.

\section{A efetivação dos direitos da criança e do adolescente por meio das Políticas Públicas}

É notório que nosso país está em crescimento e ainda em constante busca de mais crescimento, porém com um sistema precário e deficiente que não consegue cumprir de forma integral o que nossa carta magma nos traz como direitos. Essa realidade fez com que o Estado ao se deparar com problemas que o SUS não consegue comportar nem solucionar e com a falta das atenções básicas, buscasse encontrar uma solução eficaz, neste contexto, surge a proposta de implementação da(s) política(s) pública(s). As politicas públicas são desenvolvidas pela União, Estado ou Município e é composta por uma ação, metas e planos que os governos delineiam para obter o bem-estar da sociedade e o interesse público de maneira bem específica ela visa solucionar um problema detectado na sociedade, que de modo direcionado irá resolvê-lo. Ao formulador de Políticas Públicas caberá ter a percepção e compreensão a fim de que consiga escolher as mais distintas demandas (LOPES; AMARAL; CALDAS, 2008).

Barbarói, Santa Cruz do Sul, Edição Especial n.44, p.<238-254>, jul./dez. 2015 
A responsabilidade da família, da sociedade juntamente com o Estado é algo indiscutível, mas é primordialmente na instituição familiar que se concentra a maior carga, pois é nela que se estabelece a base de formação inicial do infante, pois é neste meio que ele receberá subsídios e influências para o seu desenvolvimento psicológico, cultural e social (COSTA; CASSOL, 2007).

Ressalta-se que a instituição família é onde deve ter início qualquer tipo de política social que vise proteger e garantir os direitos dos infantes dentro e fora do ambiente familiar, com isso a política de assistência social que possui força constitucional e é regulamentada por Lei Orgânica da Assistência Social não se realiza de forma eficaz, pois o Estado deve tornar viável sua implantação e se preocupar para habilitar pessoal para atuar nestas atividades (VERONESE; COSTA, 2006).

Além disso, deve-se ter um enorme cuidado com o que está disposto no Artigo $4^{\circ}$, parágrafo único, alínea “c”, do referido Estatuto que dá prioridade na hora de formular e executar as políticas sociais públicas direcionadas a esta clientela.

Com esse auxílio de prioridade absoluta que o ECA estabelece a todas as matérias referentes aos direitos das crianças e dos adolescentes, cabe a nós fomentar a utilização destes princípios.

Eis que se depara com um momento diferenciado na história dos infantes no Brasil onde se vê com maior nitidez a violência praticada contra os menores no decorrer de séculos, primeiramente pelo abandono, desrespeito e falta de consideração, visto que eram tratados como meros objetos.

Deste modo, os tratamentos abusivos do passado em relação às crianças e adolescentes ocorrem com menor frequência atualmente, uma vez que surge neste contexto legislação apropriada, direção pública e ainda políticas sociais eficazes. Esta mudança é resultado do reconhecimento dos infantes como sujeitos de direitos, que nesta condição serão capazes de no futuro, com uma visão humanizada e capacitada, criarem seus filhos longe das punições e rodeados de encantos (MAUAD, 2004).

No Rio Grande do Sul, encontra-se uma vasta lista de entidades que contribuem no auxilio e efetivação dos direitos dos infantes dentre elas destaca-se a ACBERGS ASSOCIAÇÃO DAS CRECHES DO RIO GRANDE DO SUL, que é uma entidade civil de caráter assistencial e cultural, sem fins lucrativos, que presta assessoramento a entidades ou a associações entre elas creches, que funcionam para amparo e sustento de menores carentes (ACBERGS, 2000?). 
Além disso, existe o CEDICA - Conselho Estadual dos Direitos da Criança e do Adolescente, que é um órgão público, normativo, deliberativo e controlador das políticas e das ações estaduais voltadas para os direitos da infância e juventude, sendo que suas atribuições são formular, acompanhar e controlar a política estadual de atendimento aos direitos da criança e do adolescente definindo prioridades, editando normas gerais, observando as diretrizes estabelecidas nos artigos 87 e 88 do Estatuto da Criança e do Adolescente (Lei no 8.069/90) que visa

\begin{abstract}
Apoiar os Conselhos Municipais dos Direitos da Criança e do Adolescente (CMDCA), bem como os órgãos governamentais $\mathrm{e}$ as entidades nãogovernamentais, objetivando a efetivação das normas, princípios e diretrizes estabelecidas no Estatuto da Criança e do Adolescente e gerir o Fundo Estadual para a Criança e o Adolescente fixando critérios para a captação de recursos e aplicação dos mesmos, composta por Entidades não governamentais eleitas (CEDICA, 2001?).
\end{abstract}

Atualmente temos 439 Conselhos Municipais dos Direitos da Criança e do Adolescente e 397 Conselhos Tutelares e Fundos da Criança e do Adolescente cadastrados no CEDICA (2001?).

No mesmo sentido, ainda inclui-se o CEDEDICA - Centro de Defesa dos Direitos da Criança e do Adolescente, uma associação civil sem fins lucrativos e econômicos, constituído em 18 de fevereiro de 1998, com sua sede e foro na cidade de Santo Ângelo - RS. Este órgão apoia à formação dos operadores na execução das medidas socioeducativas em geral realizadas pelos Centros de Referência de Assistência Social (CREAS), e também é responsável pela coordenação da Unidade de Semiliberdade ${ }^{2}$ desta cidade, uma vez que possui um convênio com a FASE/RS e, além disso, concretiza ações voltadas para a proteção integral à criança e ao adolescente (CEDEDICA, 2002?).

Como seus princípios utilizam o "respeito e valorização do ser humano, a ética e a transparência nas relações, bem como fomenta atitudes inovadoras, responsabilidade social e compromisso com a obtenção de resultados" (CEDEDICA, 2002?).

Encontramos também o Sistema de Garantia de Direitos da Criança e do Adolescente que tem a proposta de articular e integrar as esferas públicas governamentais com a sociedade

\footnotetext{
${ }^{2}$ Conforme prevê o Art. 120 do ECA, a medida socioeducativa de semiliberdade se caracteriza como um "regime a ser determinado desde o início ou como forma de transição para o meio aberto possibilita a realização de atividades externas, independentemente de autorização judicial". Ou seja, é uma medida que tanto poderá ser adequada para o socioeducando de primeiro ingresso, quanto para a progressão de medida, ou ainda, poderá ser aplicada como regressão de uma medida anteriormente aplicada. Informação disponível em: <http://www.fase.rs.gov.br/docs/1378989221PF_Anexo_V_PROGRAMA_GERAL_SEMILIBERDADE_RS_ FINAL_VERSAO_JULHO_2013.pdf.>. Acesso em: 14 maio de 2014.
} 
civil, aplicando organismos normativos e fazendo funcionar os meios que promovam, defenda e ou controlem atos que efetivem os direitos realçados no Estatuto da Criança e do Adolescente (SEDH, 2000?).

Este referido sistema se encontra em meio a problemas de ordem institucional, acarretando um trabalho desarticulado, contando com operadores sem qualificações adequadas causando assim prejuízos no momento de realmente implantar políticas públicas que garantam os direitos assegurados pela legislação (SEDH, 2000?).

Assim sendo, o Rio Grande do Sul, na tentativa de construir um novo paradigma de cuidados e proteção à criança, é que nasceu o PIM (Programa socioeducativo Primeira Infância Melhor) em 2003, porém só em 2006 foi reconhecido como Politica Pública de atenção integral a primeira infância que almeja desenvolver integralmente o período da primeira infância, (zero a seis anos), sendo instituído como parte integrante da Política Estadual de Promoção e Desenvolvimento da Primeira Infância, através da Lei Estadual no 12.544 de 03 de julho de 2006 (SCHNEIDER; RAMIREZ, 2007).

O PIM, foi planejado e posto em prática a partir da referência de um programa cubano, chamado "Educa tu Hijo", que possuía as mesmas premissas e princípios, utilizados para inspirar a criação desta Política Pública do Estado do Rio Grande do Sul (PIM RS, 2003).

Tal programa completou dez anos de atuação na promoção de direitos dos infantes de zero a seis anos e gestantes no ano passado, com uma ótima aceitação da sociedade, uma vez que une iniciativas do Estado e dos Municípios, da sociedade civil e das mais variadas esferas que tenham interesse e que gostariam de se comprometer com a instrução e o desenvolvimento de crianças vulneráveis daquela idade, atendendo atualmente mais de 88 mil crianças de zero a seis anos semanalmente, aproximadamente sete mil gestantes e 59 mil famílias em 253 municípios do Rio Grande do Sul (PIM RS, 2003).

Este Programa do governo do Estado do Rio Grande do Sul visa à efetivação dos direitos da criança, valorizando dessa forma seu desenvolvimento sadio, além de buscar a transformação da realidade infantil brasileira, de crianças de zero a seis anos, gestantes e suas famílias.

Sua meta é garantir a satisfação dos direitos na Primeira Infância. O PIM está presente, principalmente nas comunidades em que existe um número elevado de crianças nesta faixa etária e gestantes, além de atuar em comunidades carentes e vulneráveis, seu trabalho também aparece em locais que existam um número baixo ou nenhuma escola de Educação Infantil. 
Esta Política Pública Estadual é proposta com base em estudos que comprovaram a importância dos primeiros anos de desenvolvimento do ser humano. Sendo assim o Rio Grande do Sul, viu a necessidade de implantar uma Política Pública para promoção e desenvolvimento integral da Primeira Infância Melhor. Seu objetivo principal é de orientação das famílias, a partir de sua cultura e experiências, para que se promova o desenvolvimento integral das crianças desde a gestação até os seis anos de idade, e redobrando os cuidados no período de zero a três anos (PIM RS, 2003).

Encontra-se com muita veemência nesta Política Pública a efetivação dos direitos da criança, valorizando dessa forma seu desenvolvimento sadio, ela tem como objetivo geral transformar a realidade infantil brasileira, de crianças de zero a seis anos, garantindo a satisfação dos direitos na Primeira Infância, além de buscar um crescimento saudável proporcionando uma educação melhor aproveitada, de modo a combater a violência (SCHNEIDER; RAMIREZ, 2007).

O mencionado programa busca conferir a estas crianças um crescimento saudável proporcionando uma educação melhor aproveitada, de modo a combater a violência pela ótica da promoção e desenvolvimento da primeira infância, nas dimensões física, psicológica, intelectual e social.

Sua execução é feita pelos municípios ou organizações não governamentais que aderem ao programa através de um termo firmado pelo Secretário do Estado e Prefeito Municipal ou por quem se responsabilize pela ONG, sempre apoiados pelas Coordenadorias Regionais de Saúde e Coordenadorias Regionais de Educação (SCHNEIDER; RAMIREZ, 2007).

O programa organiza-se em torno de três eixos estruturantes: a Família, a Comunidade e a Intersetorialidade: "A família é concebida como o grupo humano primário mais importante nos anos iniciais da vida de todo indivíduo" (SCHNEIDER; RAMIREZ, 2007, p.52).

A comunidade é concebida no Programa como um espaço fundamental de potencialidades, recursos humanos, materiais e institucionais. Seus costumes, suas tradições, suas produções culturais são elementos importantes na educação, na saúde e no desenvolvimento das crianças (SCHNEIDER; RAMIREZ, 2007).

A intersetorialidade no atendimento às crianças, como um dos eixos estruturantes do PIM, decorre da constatação de que a fragmentação das iniciativas, a setorialização excessiva e a ênfase na especialização das ações resultam em políticas inadequadas e em programas pontuais que, além de dispersar os recursos, reduzem sua eficácia e efetividade, se definindo 
como um conjunto articulado de ações em rede de apoio à gestante, à criança de zero a seis anos e às suas famílias (SCHNEIDER; RAMIREZ, 2007).

Ocorre que nesta politica pública existe um cuidado extremamente pontual do eixo gestante e bebê e ela os atende de duas formas: a modalidade individual que atende as crianças de zero a dois anos e 11 meses de idade, bem como às gestantes vinculadas ao Programa, sendo a modalidade dirigida às crianças é semanal e a modalidade dirigida às gestantes é quinzenal, ambas são realizadas na residência da família, com a duração de aproximadamente uma hora, e a modalidade de grupos que é dirigida às famílias com crianças de três a seis anos de idade, bem como às gestantes, ocorrendo uma vez por semana ou uma vez por mês, respectivamente (SCHNEIDER; RAMIREZ, 2007, p.67).

O trabalho é desenvolvido em associações comunitárias, salões paroquiais, parques infantis e nos lares dos integrantes do programa. Seu objetivo é respeitar e promover as diferentes fases do desenvolvimento integral de cada criança nesta etapa de interação e convivência social. A modalidade se dá através de jogos, atividades lúdicas e educativas, planejadas pelos visitadores, sob a orientação de um monitor (SCHNEIDER; RAMIREZ, 2007).

Os grupos de gestantes têm como objetivo maior levar informações relevantes sobre a importância da amamentação, sobre o parto, entre outras, além de promover a socialização e a troca de experiências (SCHNEIDER; RAMIREZ, 2007).

Em 2011 o programa foi avaliado em dezesseis principais cidades que têm o PIM implementado, e nesta avaliação feita com as famílias atendidas constatou-se que

97\% declararam ter modificado o modo de tratar o filho/a e $92 \%$ que o PIM colaborava com a saúde dele/a; $96 \%$ das famílias disseram participar semanalmente das atividades do PIM; 77\% alcançaram os resultados esperados para as atividades e 22\% alcançaram em parte (PIM RS, 2011)

Cabe ressaltar que, apesar da existência dessa política pública direcionada à infantes de até seis anos de idade, temos ainda o coroamento a nível nacional com a união do Programa Bolsa Família e do PETI - Programa de Erradicação do Trabalho Infantil, a fim de impedir a exploração de crianças e adolescentes, e também para facilitar a fiscalização pelo Governo, tornando efetiva a aplicação destes programas na sociedade brasileira.

O MDS (Ministério do Desenvolvimento) faz questão de deixar claro que

O Programa de Erradicação do Trabalho Infantil (Peti) e o Bolsa Família foram integrados mantendo suas especificidades e objetivos, não havendo sobreposição de um sobre o outro. Ao mesmo tempo em que agem de forma conjunta, ambos os programas também buscam a inserção das famílias em projetos, serviços e ações 
socioassitenciais que visam à preservação dos vínculos familiares e da convivência comunitária (PETI, 2010?).

Todavia, a maior preocupação do Governo é de proporcionar o desenvolvimento saudável destas crianças, dando continuidade às propostas do PIM através de outras Políticas Públicas, restando este ciclo completo e só então efetivamente garantido os direitos de proteção ao infante durante toda esta etapa, pois se acredita que não só a Primeira Infância Melhor deve ser priorizada, e sim todo o período de formação, desde a infância até a adolescência, deixando para o futuro um cidadão bem desenvolvido e amparado, uma vez que seus direitos de infante foram garantidos por estes programas, refletindo essas garantias em sua vida adulta.

Diante de todos os fatos anteriormente relatados, parece necessário uma real efetivação também na prática social dos direitos dos infantes, de forma que para erradicar a violência é preciso não apenas legislações avançadas, mas sim, primeiramente a solidificação das já existentes, a fim de aproximar todos os meios e políticas voltadas a este projeto, tornando-os unos e eficazes.

A medida e o alcance deste novo paradigma social, ocorrerá no instante em que se consiga fortalecer a tríplice cooperação das instituições anteriormente referidas que se apresentam na efetivação dos direitos dos infantes de forma a abolir a violência intrafamiliar e todas as formas de supressão aos direitos dos infantes.

Ademais, é fundamental que os municípios obtivessem autonomia para criação de uma delegacia especializada para repressão aos crimes contra crianças e adolescentes, mas nem o ECA ou qualquer outra lei federal obriga a criação das referidas delegacias. A existência de unidades especializadas seria um grande avanço político-institucional para o País, como ocorreu com a criação da delegacia de mulheres, considerando que essas delegacias seriam muito importantes na investigação dos abusos e crueldades cometidas contra crianças e adolescentes.

Sabe-se que na ausência das delegacias especializadas, os procedimentos relativos a esse tipo de ocorrências são realizados pelas Delegacias comuns que nem sempre priorizam essas apurações além de não disporem de pessoal especializado e/ou capacitado para realização da tarefa. Estas crianças devem ser encaminhadas ao CREAS (Centro de Referência Especializado de Assistência Social) que tem por finalidade atender criaças e adolescentes que tiveram seus direitos violados, e na sua falta, serão atendidas pelo CRAS. 
No entanto em linhas conclusivas, se faz necessário conclamar a classe política de forma a sensibilizá-la e envolver os gestores, através de um efetivo atuar, tanto no papel de fiscalização, quanto de controle social.

Assim, também se deve destacar que são necessários novos investimentos sempre primando dar vida a essa legislação para que partindo disso se tenha como garantir de fato e de direito, os direitos das crianças, proporcionando-lhes de tal forma a integralidade do seu desenvolvimento (SCHNEIDER; RAMIREZ, 2007).

\section{Considerações Finais}

Claramente se nota que o Brasil vem evoluindo quanto a proteção dos direitos da criança, já que o próprio ordenamento jurídico, no âmbito do Estatuto da Criança e do Adolescente passou a estabelecer que os infantes são pessoas merecedoras da proteção integral, devendo o próprio Estado garantir a efetivação de seus direitos em todas as fases de sua existência.

Ao conhecer melhor o Programa Primeira Infância Melhor torna-se cristalino que os direitos das crianças estão sendo garantidos, já que uma vez priorizada a primeira infância, entende-se que as crianças possuirão acesso efetivo à Saúde e Educação, de modo a proporcionar um futuro mais digno e saudável, logo, sem violência.

Contudo, muita coisa ainda precisa ser realizada, principalmente o desenvolvimento sadio e completo desses infantes, priorizando as famílias de baixa renda e de condições mínimas, que por muitas vezes se concentram principalmente no Norte e Nordeste do País.

Sendo assim, é de extrema importância essa Política Pública para promoção da Primeira Infância, bem como, os resultados quando ela é evidenciada, mostrando que o governo se importa e pretende melhorar a situação dos infantes desta faixa etária.

No Brasil ainda é bastante frágil o processo de avaliação das políticas públicas. Por questões politicas, corrupção, descrédito nas instituições representativas do governo, etc., a avaliação das mesmas acabam tendo pouca credibilidade junto a sociedade. É necessário, portanto, a conscientização da real importância que esta fase assume no processo de estudo e análise de uma política pública, bem como um olhar diferenciado sobre a perspectiva do tipo de dimensão ao caso concreto são de extrema importância para que do processo avaliativo possa surgir uma outra construção que torne-se efetiva e contemple as reais necessidades dos infante no Brasil.

Barbarói, Santa Cruz do Sul, Edição Especial n.44, p.<238-254>, jul./dez. 2015 
Nessa perspectiva, as políticas públicas não devem ser entendidas como programas que se dividem por setores de acordo com as necessidades do Estado, ao contrário, elas devem estar interligadas de maneira contínua e serem compreendidas a partir da própria construção de instituição e processo políticos, que estão intimamente interligados com todas as questões que regem uma sociedade.

Por fim, com base em pesquisas, o governo do Estado do Rio Grande do Sul, foi muito aplaudido com a criação dessa Política Pública. Essa política corrobora com o ênfase dado pela agenda mundial à primeira infância, e com este programa, o governo auxilia e proporciona no desenvolvimento sadio e integral das gestantes e crianças de zero à seis anos, para que essa etapa da vida seja marcada sempre por desenvolvimento e não por carências, sejam elas físicas ou psicológicas.

\section{Referências}

ACBERGS. Associação das Creches do Rio grande do Sul. Disponível em: <http://www.rs.gov.br/direciona.php?key=Y2FwYT0xJmludD1ub3RpY2lhJm5vdGlkPTY0O DAwJnBhZz0xJmVkaXRvcmlhPTEyNiZvcmlnPTE>. Acesso em: 10 maio 2013.

BARROS, M.E. Políticas de Saúde no Brasil: diagnóstico e perspectivas. Brasília: IPEA, 1996.

BRASIL. Estatuto da Criança e do Adolescente (ECA). Lei no ${ }^{\circ} 8.069$ de 13 de julho de 1990. Disponível em: <http://www.planalto.gov.br/ccivil_03/leis/18069.htm>.Acesso em: 13 abr 2013

CEDEDICA. Centro de Defesa dos Direitos da Criança e do Adolescente. Disponível em: $<$ http://www.cededica.org.br/uploads/estatuto_atuatualizado.pdf $>$. Acesso em:10 maio de 2013.

CEDEDICA. Centro de Defesa dos Direitos da Criança e do Adolescente. Disponível em: $<$ http://www.cededica.org/web/missao_visao>. Acesso em: 10 maio 2013.

CEDICA. Conselho Estadual dos Direitos da Criança e do Adolescente. Disponível em: $<$ http://cedica.rs.gov.br/>. Acesso em: 10 maio de 2014.

CEDICA. Conselho Estadual dos Direitos da Criança e do Adolescente. Disponível em: <http://cedica.rs.gov.br/>. Acesso em: 10 maio de 2013.

COSTA, Marli M. M. da. (org.) Sabrina Cassol. Direito, cidadania e políticas públicas II: Direito do cidadão e dever do Estado. Porto Alegre: Imprensa Livre. 2007. 
CUSTÓDIO, André Viana; VERONESE, Josiane Rose Petry Trabalho Infantil a negação do ser criança e adolescente no Brasil. Florianópolis: OAB/SC Editora, 2007.

LOPES, Brenner; AMARAL, Jefferson Ney; CALDAS, Ricardo Wahrendorff (coord.) Políticas Públicas: conceitos e práticas. Belo Horizonte: Sebrae/MG, 2008.

MAUAD, Ana Maria. A vida das crianças de elite durante o império. In: PRIORE, Mary del (Org.). História das Crianças no Brasil. 4 ed. São Paulo: Contexto, 2004.

MENICUCCI, Telma. A implementação da Reforma Sanitária: a formação de uma política. IN: HOCHMAN, Gilberto; ARRETCHE, Marta; MARQUES, Eduardo Cesar (Org.). Políticas Públicas no Brasil. Rio de Janeiro: FIOCRUZ, 2007.

MINISTÉRIO DO DESENVOLVIMENTO SOCIAL E COMBATE À FOME. Programa Brasil carinhoso. Disponível em: <http://www.mds.gov.br/brasilsemmiseria/brasilcarinhoso>. Acesso em: 28 abr 2014

MIRANDA, Maria Inês Ferreira de; FERRIANI, Maria das Graças C. Políticas públicas sociais para crianças e adolescentes. Goiânia: AB, 2001.

Programa Erradicação do Trabalho Infantil (PETI). Disponível em: <http://www.mds.gov.br/ assistenciasocial/peti/integracao-peti-e-bolsa-familia>. Acesso em: 28 abr 2014.

FASE. Programa Geral Semiliberdade. Disponível em:

<http://www.fase.rs.gov.br/docs/1378989221PF_Anexo_V_PROGRAMA_GERAL_SEMIL IBERDADE_RS_FINAL_VERSAO_JULHO_2013.pdf.>. Acesso em: 14 maio de 2014.

PIM. Programa Primeira Infância Melhor. Disponível em:

$<$ http://www.pim.saude.rs.gov.br/a_PIM/php/paginaIndicadoresSucessoPim.php $>$. Acesso em: 10 maio de 2013.

PIM. Programa Primeira Infância Melhor. Disponível em: <http://www.pim.saude. rs.gov.br/a_PIM/boletinsInformativos/Boletim-EdicaoEspecial-

SegundoCorteAvaliativo.pdf>. Acesso em: 28 abr 2014.

SALIBA, Maurício Gonçalves. O olho do Poder: análise critica da proposta educativa do Estatuto da criança e do adolescente. São Paulo: Unesc, 2006.

SCHNEIDER, Alessandra; RAMIRES, Vera Regina. Primeira Infância Melhor: uma inovação em política pública. Brasília: UNESCO e Secretaria de Saúde do Estado do Rio Grande do Sul, 2007.

SEDH. Sistema de Garantia de Direitos. Disponível em:

<http://www.sedh.gov.br/clientes/sedh/sedh/spdca/sgd>. Acesso em: 10 maio de 2013.

UNICEF. Declaração Universal dos Direitos da Criança. Nova Iorque: UNICEF, 1959.

Disponível em:< http://www.direitoshumanos.usp.br/index.php/Crian\%C3\%A7a/declaracaodos-direitos-da-crianca.html>. Acesso em:10 maio 2012.

VERONESE, Josiane R. P. COSTA, Marli Marlene M. da. Violência Doméstica: Quando a vítima é criança ou adolescente. Uma leitura interdisciplinar. Florianópolis: OAB/SC, 2006. 
. Os Direitos da Criança e do Adolescente. São Paulo: LTr, 1999.

Humanismo e infância: a superação do paradigma da negação do sujeito. In:

MEZZAROBA, Orides (Org.). Humanismo latino e estado no Brasil. Florianópolis: Fundação Boiteux [Treviso]: Fondazione Casamarca, 2003.

\section{Sobre as autoras:}

Cleidiane Sanmartim é Mestranda em Direito com Bolsa Capes/Prosup pelo PPGD - UNISC. Bacharel em Direito da Universidade de Santa Cruz do Sul - UNISC. Integrante do grupo de pesquisa: "Direito, Cidadania e Políticas Públicas", coordenado pela professora Pós-Doutora Marli Marlene Moraes da Costa, vinculado ao Programa de Pós-Graduação em Direito Mestrado e Doutorado da Unisc e certificado pelo CNPq. Bolsista de Iniciação Científica PUIC no projeto de pesquisa "O direito de proteção contra a exploração do trabalho infantil e as políticas públicas educacionais no Brasil”, coordenado pela professora Pós-Doutora Marli Marlene Moraes da Costa. Endereço eletrônico: cleidisan@ hotmail.com

Josiane Borghetti Antonelo Nunes é Advogada e professora no Curso de Direito da Universidade de Santa Cruz do Sul. Possui graduação em DIREITO pela Universidade de Santa Cruz do Sul (2004), atualização na AJURIS (2005) e mestrado em Direito pela Universidade de Santa Cruz do Sul (2009). Integrante do Grupo de Estudos Direito, Cidadania e Políticas Públicas, do Programa de Pós-Graduação em Direito, Mestrado e Doutorado, da Universidade de Santa Cruz do Sul UNISC. Endereço eletrônico: jbantonelo@gmail.com 